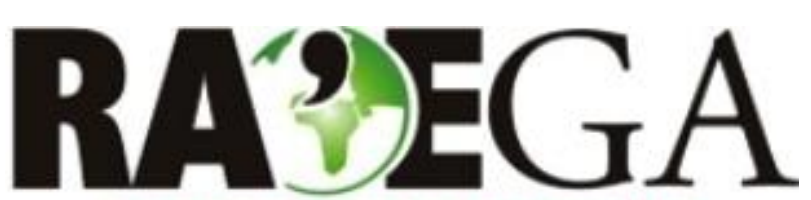

O ESPACYO GEOGRÁFICO EM ANÁLISE

\title{
LIGAS MUNICIPAIS E COPA DOS RIOS DE SELEÇÕES: INTEGRAÇÃO DO ESPAÇO AMAZONENSE ATRAVÉS DA CENTRALIDADE SUBTERRÂNEA
}

\section{MUNICIPAL LEAGUES AND COPA DOS RIOS DE SELEÇÕES: INTEGRATION OF THE AMAZONAS SPACE THROUGH THE UNDERGROUND CENTRALITY}

\author{
Fernando Rosseto Gallego Campos \\ Instituto Federal de Santa Catarina \\ Chapecó, SC, Brasil \\ e-mail: fgallego@gmail.com
}

Recebido em: 06/03/2015

Aceito em: 29/02/2016

\section{Resumo}

O futebol amador organizado pela Federação Amazonense de Futebol (FAF) através de ligas municipais e da Copa dos Rios de Seleções - consegue promover a integração do espaço amazonense de forma que o futebol profissional não é capaz. Assim, o presente artigo tem como objetivo analisar como as ligas municipais e a Copa dos Rios de Seleções integram o espaço simbólico do futebol amazonense através da centralidade subterrânea. Para tal, é proposta, baseada em Foucault (2006), uma espacialização do futebol em três dimensões: discursiva, prática e institucional. Os dados utilizados foram obtidos através de observações de campo e entrevistas realizadas em 2007, 2008 e 2015 (em Manaus e Parintins), bem como pesquisa documental. As entrevistas realizadas foram analisadas através da Análise do Discurso. As ligas municipais - que formam seleções para disputar a Copa dos Rios de Seleções - se organizam através da centralidade subterrânea e do sentimento comunitário, articulando diferentes atores socioespaciais dos municípios. Apesar das grandes distâncias, a Copa dos Rios de Seleções consegue integrar praticamente todos os municípios do interior do Amazonas (em 2013 e 2014, reuniu 54 dos 61 municípios possíveis). Para dirigentes e participantes, a Copa dos Rios de Seleções é o verdadeiro campeonato amazonense, sendo capaz de articular mais de $80 \%$ dos municípios do interior do estado por edição, bem como diferentes atores socioespaciais, tais como jogadores, árbitros, poder público, empresários, entre outros. 
Palavras-chave: Futebol; Futebol Amador; Amazonas

\begin{abstract}
The amateur football organized by the Amazonas Football Federation (AFF) through municipal leagues and Copa dos Rios de Seleções - promotes the integration of the Amazonas space in a way that the professional football does not manage to. Thus, the present study aims at analysing how municipal leagues and Copa dos Rios de Seleções integrate the symbolic space of the Amazonian football through the underground centrality. In order to reach this goal, based on Foucault (2006), a three-dimensional spatialization of football is proposed: discursive, practical, and institutional. Data for the analysis were gathered through field observation and interviews conducted in the years 2007, 2008, and 2015 (in Manaus and Parintins) as well as document research. Te interviews were analysed under the lights of Discourse Analysis. The municipal leagues - that join selections to dispute Copa dos Rios de Seleções - are organized through underground centrality and community feeling, articulating different municipal actors. In spite of the great distances, Copa dos Rios de Seleções manages to integrate nearly all inner municipality in Amazonas (in 2013 and 2014, put together 54 out of 61 possible municipality). For both managers and participants, Copa dos Rios de Seleções is the real Amazonas championship, being able of articulate over $80 \%$ of the municipalities by edition, as well as different sociospatial actors, such as players, football referees, public power, businessmen, among others.
\end{abstract}

Keywords: Football; Amateur football; Amazonas

\title{
1. INTRODUÇÃO
}

É inegável que o futebol seja um fundamental componente da sociedade brasileira e mundial, já que sua prática social se encontra intimamente ligada à vida cotidiana. Sendo assim, ele transcende sua dimensão esportiva e se torna importante elemento sociocultural e na produção espacial - tanto material quanto simbólica (MASCARENHAS, 1999, 2013; TOLEDO, 2001, 2013; DAMATTA, 2003; GALLEGO CAMPOS, 2006, 2008, 2010; DAMO, 2008, 2012; ALABARCES, 2011; ALMEIDA, 2011; FRANCO JÚNIOR, 2013). Localmente, é capaz de gerar complexas estruturações identitárias, fortemente calcadas na vida cotidiana e em elementos simbólicos (HAESBAERT, 2003, 2008; MAFFESOLI, 2006, 2007).

No caso do Amazonas, o futebol amador constrói espacializações múltiplas, mais complexas e abrangentes do que o futebol profissional - restrito 
espacial e esportivamente ${ }^{1}$. Em um estado com $1.570 .746 \mathrm{~km}^{2}$ e precária rede de comunicações e transportes, o futebol amador acaba sendo uma das principais manifestações do globalismo amazônida, graças a uma organização que rompe com a rigidez institucional do futebol profissional e através da centralidade subterrânea consegue penetrar e integrar diferentes municípios e comunidades.

Derivada da concepção do paradigma da socialidade, a centralidade subterrânea denota uma organização horizontal e reticular, através da qual as tribos (grupos afetuais, pautados em uma lógica de estruturações identitárias híbridas e fluidas) se relacionam em seu interior e com outras tribos, a partir da potência (MAFFESOLI, 2006). Enquanto o poder é vertical, extrínseco e fundamentado no (e fundamento do) indivíduo e nas instituições modernas, a potência é horizontal em sua circulação, pois tem caráter intrínseco às comunidades (massas e tribos) pelas quais circula. A potência produz representações sociais, que circulam através de uma centralidade subterrânea, ou seja, a maneira pela qual as comunidades afetivas se estruturam, se consolidam e se solidificam em um conjunto autônomo e de dinâmica específica (MAFFESOLI, 2006).

As ligas municipais e a Copa dos Rios de Seleções, organizada pela Federação Amazonense de Futebol (FAF), são duas destas formas de integração espacial (tanto no sentido físico quanto no simbólico). Assim, o objetivo deste artigo é analisar como as ligas municipais e a Copa dos Rios de Seleções integram o espaço simbólico do futebol amazonense, através da centralidade subterrânea. Para tal temos com objetivos específicos propor uma espacialização do futebol em três dimensões - discursiva, prática e institucional

\footnotetext{
O futebol profissional amazonense não conta com nenhum representante nas Séries $A, B$ e $C$ do futebol brasileiro (na Série $D$ cada estado tem direito a duas vagas). O Campeonato Amazonense reúne 10 clubes, distribuídos em 5 municípios: Manaus (Nacional, Fast Clube, São Raimundo, Rio Negro e Manaus); Manacapuru (Operário e Princesa do Solimões); Iranduba (Iranduba); Itacoatiara (Penarol); e Borba (Nacional Borbense). Há uma forte concentração de clubes e títulos na capital (das 98 edições, apenas 5 tiveram campeões do interior, sendo a primeira vez em 2005). Além do fraco nível técnico dos clubes, o Campeonato Amazonense não tem grande penetração na vida cotidiana do Amazonas, com baixas médias de público e pouco espaço na mídia local e nacional. Outro importante dado é a preferência por clubes de fora. Em uma pesquisa de torcida em Manaus, divulgada em setembro de 2012, os clubes amazonense não somaram juntos nem 1\%, enquanto clubes cariocas chegaram a $68 \%$ (50\% só o Flamengo) (Globoesporte 2012). Em outra pesquisa do Instituto de Pesquisa do Norte (IPEN), de 2012, quando questionados para que time local torciam, $49,5 \%$ declararam torcer para nenhum clube (IPEN 2012)
} 
- baseadas em Foucault (2006); e discutir o futebol amador amazonense vinculado à FAF a partir da espacialização do futebol supracitada.

O futebol, essencialmente, possui uma forte dimensão espacial tanto material quanto, sobretudo, simbólica. A materialidade do futebol - por vezes óbvia nos estádios e demais equipamentos esportivos; nas sedes de clubes, federações, torcidas organizadas e outras instituições; no comércio; e em tantos outros territórios futebolísticos - tem natureza predominantemente político-econômica (HAESBAERT, 2003, 2008; MASCARENHAS, 2013). Discutir a materialidade do espaço do futebol é de grande importância, mas nossa abordagem privilegia a dimensão simbólica da espacialidade futebolística. Isto não significa ignorar a dimensão material, mas considerá-la relevante como forma de compreender as relações simbólicas.

\section{METODOLOGIA}

Os dados para este estudo foram obtidos em três etapas. A primeira delas ocorreu entre junho e julho de 2007, através de uma viagem ao longo dos Rios Madeira, Negro e Amazonas, promovida por uma parceria entre a Universidade Federal do Paraná (UFPR) e a de Rondônia (UNIR). Nesta etapa foram realizadas entrevistas com diversos atores socioespaciais do futebol amador amazonense, mas neste artigo foram analisadas as entrevistas de: Elton Ferreira da Silva, presidente da Associação Liga Desportiva de Parintins e Renato Barros Jesus, jogador da liga amadora de Parintins. Ambas entrevistas foram realizadas presencialmente em Parintins, gravadas e, posteriormente, transcritas.

A segunda etapa aconteceu em setembro de 2008, em Manaus, na ocasião da abertura e da primeira semana do Campeonato de Peladas do Amazonas (Peladão). Também foram entrevistados vários atores socioespaciais, mas foram selecionadas duas entrevistas para análise: Lázaro D'Angelo Pinheiro, na época, diretor técnico e de eventos da FAF, e José Roberto Moreira da Rocha, secretário do Tribunal de Justiça Desportiva do Amazonas. Ambas entrevistas foram feitas presencialmente em Manaus, gravadas e, posteriormente, transcritas. 
Optou-se por entrevistas abertas não estruturadas para permitir maior liberdade discursiva dos entrevistados (apesar de, como veremos a frente, o discurso é permeado por interditos ligados ao poder e à função na política institucional) e para apreender impressões pessoais, valores e dimensões simbólicas, que poderiam ser negligenciadas na aplicação de questionários ou entrevistas semiestruturadas. A escolha pelos entrevistados se deu por critérios qualitativos, ou seja, a relevância do discurso deles para a compreensão das peculiaridades da espacialização futebolística do futebol amador do Amazonas.

A terceira etapa ocorreu em fevereiro e março de 2015, através de pesquisa documental, com entrevistas, bem como com contatos telefônicos e por e-mail com atores socioespaciais já entrevistados nas duas primeiras etapas, a fim de atualizar e legitimar o conteúdo das entrevistas. O único contato por telefone e por e-mail que gerou novas informações foi com Lázaro D'Angelo Pinheiro, Diretor de Futebol do Interior da FAF. A pesquisa documental englobou documentos fornecidos pela FAF, bem como notícias e reportagens de sites locais sobre a Copa dos Rios de Seleções.

Para a análise das entrevistas realizadas na primeira e na segunda etapa, bem como das informações obtidas por e-mail e contato telefônico, além das declarações contidas nas notícias e reportagens, na terceira etapa, utilizamos os procedimentos da Análise do Discurso (AD) (MAINGUENEAU, 1997; PÊCHEUX, 2014; ORLANDI, 1998, 2009; FOUCAULT, 2007).

\subsection{Análise do Discurso}

O discurso é composto por uma diversidade de efeitos de sentido, de ditos e não-ditos, que se relacionam conforme as condições de formação, ligadas ao processo discursivo (PÊCHEUX, 2014). Estas condições são influenciadas por alguns fatores: lugar e cena; gêneros de discurso; autoridade; cenografia e dêixis; além do ethos (MAINGUENEAU, 1997). Foucault postula sobre a ordem do discurso, dizendo ser este altamente articulado com a configuração social e suas coerções. Desta forma, o discurso não é aleatório, ou seja, pressupõe coerções, relações de poder (e em uma visão maffesoliana, de potência), enunciatários específicos, entre outros fatores que são, ao 
mesmo tempo, produtos das relações sociais e produtores destas. Portanto, admitimos que estas características estão presentes no próprio discurso produzido nas entrevistas. O enunciador não controla plenamente seu discurso. Ele é influenciado também pelo seu enunciatário e pelo contexto em que é produzido o discurso. Assim, é possível que haja diferenças entre o discurso (o que se diz, como se diz, o que não se diz, etc.) produzido para um meio de comunicação e para em pesquisador (e, consequentemente, todos os leitores desta produção científica).

Apesar da centralidade do poder nas formulações foucaultianas, podemos transcender estas coerções também à centralidade subterrânea ou à potência, que apesar de seu caráter horizontal ora admite e ora exige determinadas coerções, como forma de controle interno das tribos. Assim, não apenas as funções contratuais exigem determinados discursos, mas os papéis exercidos nas tribos, mesmo de maneira menos rígida, também sugerem uma regularidade discursiva ao enunciatário: "ninguém entrará na ordem do discurso se não satisfizer a certas exigências ou se não for, de início, qualificado para fazê-lo" (FOUCAULT, 2007, p. 37). Para Foucault, o indivíduo - produto do poder - não reúne condições de formular seu próprio discurso, que Ihe é praticamente imposto. Na perspectiva de Maffesoli (2006), a pessoa (persona) imersa em uma ou mais tribos também não pode discursar livremente. Isto ocorre não porque as tribos não permitem, mas porque elas impõem uma ordem fusional, ou seja, para fazer parte de uma tribo, a pessoa deve/pode anular determinados aspectos de sua individualidade. Em outras palavras, a pessoa só é pessoa na medida em que se insere numa tribo e nela desempenha papéis, portanto só pode discursar de dentro desta tribo, falando como representante ou membro desta.

Assim, é possível se falar em uma rede de formulações, preenchidas por regularidades, na qual os sujeitos e as pessoas se inserem (PÊCHEUX, 2014). Estas redes se encontram no interior de formações discursivas (FOUCAULT, 2007), que pressupõem que os enunciados, em suas diferentes formas, apresentem um conjunto possuidor de certas regularidades. De acordo com a visão de Pêcheux (2014), o discurso apenas se torna dotado de sentido ao 
pertencer a uma dada formação discursiva. Isto porque os efeitos de sentido não existem independentemente da conjuntura em que estão inseridos, das relações de força inerentes aos processos sócio-históricos.

A partir desta perspectiva da $A D$, realizamos a análise das entrevistas, considerando o conteúdo transcrito, bem como aquilo que só se pode captar no áudio, como o tom da voz e emoções. As informações obtidas foram cruzadas com observações em campo, documentos e notícias/reportagens, a fim de apreender a espacialização do futebol amador do Amazonas.

\section{RESULTADOS E DISCUSSÕES}

\subsection{Espacialização do futebol}

Para realização de uma espacialização do futebol, partimos da interpretação da espacialização da doença que Foucault (2006) propõe em $O$ Nascimento da Clínica. O autor fala em três diferentes formas de espacialização: (1) a da classificação das doenças (nosologia); (2) a da prática da investigação das patologias; e (3) a das instituições médicas. É possível conceber estas três formas de espacialização, respectivamente, como: (1) discursiva, (2) prática e (3) institucional. Desta forma, para compreender a espacialização do futebol amazonense, é necessário entender de que maneira elas se inter-relacionam.

A espacialização discursiva, em suas diferentes formas e modulações, é uma das principais formas de expressão das relações simbólicas, dentre elas o ethos futebolístico, as emoções, as estruturações identitárias futebolísticas, os mitos e os símbolos. A partir da espacialidade de Lefebvre, Shields (1999), identifica dois tipos de discursos: (1) discursos sobre o espaço e (2) discursos do espaço. O primeiro tipo de discurso está ligado às representações do espaço, de modo a ser expressão de sentidos da enunciação racionalizada dos planejadores e técnicos do espaço. Já o segundo, remete aos espaços de representação, sendo produzido pelas experiências de momentos, pela experiência plena da espacialidade, sendo, portanto, expressões legítimas do próprio espaço social. Estes dois tipos de discursos travam um embate pela 
primazia da significação espacial.

Sendo a espacialização discursiva uma das melhores formas de se apreender as relações simbólicas da espacialização futebolística - justamente por que expressa também tanto a espacialização prática quanto a institucional - utilizamos a AD como abordagem teórica, mas também metodológica, para compreender de que forma os elementos simbólicos futebolísticos são apropriados, (re)significados e comunicados.

A espacialização prática (neste caso seria mais adequado falar em espacialização das práticas, pois as práticas futebolísticas são bastante diversas) se refere às apropriações simbólicas vinculadas ao fato futebolístico e às práticas sociais ligadas a ele. Desta forma, abrange desde o jogar até 0 torcer (inclusive os símbolos e mitos construídos como referência de tais práticas); desde os objetivos até as emoções e os valores. Tem forte ligação com a prática social da vida cotidiana, pois o futebol faz parte desta vida cotidiana. Assim, ele pode ser apreendido como, ao mesmo tempo, um produtor e um produto de representações sociais; através das quais o mundo cotidiano apresenta-se como coerente e dotado de sentido para as pessoas, que partilham uma realidade subjetivamente significativa (MOSCOVICI, 2003). Desta forma, a prática social do futebol penetra na prática espacial cotidiana, fazendo com que ela seja puncionada por momentos de presença (LEFEBVRE, 2006).

A prática social do futebol se organiza na escala do tátil, no encontro (para jogar torcer, etc.), se constituindo como importante manifestação de sociabilidade e, na leitura maffesoliana, da socialidade (MAFFESOLI, 2006). Assim, favorece pulsões gregárias, de caráter trágico-dionisíaco. No entanto, a prática social do futebol não se dá apenas no face a face, podendo também ser mediada, sobretudo pela mídia. Esta mediação é mais comum no futebol profissional, mas também ocorre no futebol amador, através das coberturas jornalísticas e eventuais transmissões dos jogos (principalmente por rádio).

A espacialização institucional está intimamente ligada com a espacialização prática. Ela se refere às relações - de poder e/ou de potência

- entre instituições e seus atores socioespaciais (e das apropriações 
simbólicas realizadas a partir da prática). Tais relações têm caráter político, mas no caso do futebol, têm forte dimensão simbólica, devido às apropriações do futebol em nossa sociedade (TOLEDO, 2001, 2013; GALLEGO CAMPOS, 2006, 2008, 2010; DAMO, 2008, 2012; FRANCO JÚNIOR, 2013).

Quanto mais próximas da política institucional oficial da Fédération Internationale de Football Association (Fifa) e da International Board (IB), mais as relações se tornam dotadas de significado político-institucional e menos livres de coerções das regras estabelecidas (futebolísticas ou institucionais) se apresentam. O contrário também se aplica, de modo que quanto mais distante de compromissos com o sistema Fifa-IB, mais a espacialização institucional se torna livre e fluida. Damo (2005) denomina de matriz bricolada aquela que não segue os padrões das instituições oficiais do futebol. Neste caso, o que caracteriza como fato futebolístico se define mais simbolicamente do que institucional ou normativamente, ou seja, não segue as mesmas regras do futebol profissional (matriz espetacularizada), mas pode ser identificado por futebol pelos atores que 0 praticam porque se apropria de elementos simbólicos singulares (desde a bola até qualquer outra coisa que possa ser chutada; desde uma trave de metal/madeira até um gol improvisado; etc.) (DAMO, 2005; GALLEGO CAMPOS, 2010).

Entre o extremo da matriz espetacularizada e da bricolada, há uma imensa gama de matizes de significações dadas ao fenômeno futebolístico e, portanto, uma grande diversidade de espacialidades institucionais, derivadas de diferentes apropriações simbólicas, atores socioespaciais envolvidos, compreensões e aplicações de regras, bem como instituições à qual estão vinculadas. No caso das ligas municipais e da Copa dos Rios de Seleções, há uma espacialização institucional híbrida ora se aproximando do sistema Fifa-IB (à qual são vinculadas institucionalmente, através da FAF) ora se aproximando de práticas mais fluidas e se organizando reticularmente através da centralidade subterrânea (MAFFESOLI, 2006; GALLEGO CAMPOS, 2010).

\subsection{Ligas Municipais}

Os campeonatos atrelados à FAF possuem forte articulação institucional 
com a escala nacional - já que a FAF é vinculada diretamente à Confederação

Brasileira de Futebol (CBF) - e global, pois utiliza as regras padrão do futebol internacional. No entanto, esta configuração organizacional não enfraquece as peculiaridades locais, principalmente no caráter afetual e tribal da espacialização prática do futebol amador do Amazonas. Mesmo que a FAF esteja inserida no sistema Fifa-IB, próprio da matriz profissional, a organização reticular em ligas municipais remete à centralidade subterrânea, dando um caráter híbrido à espacialização institucional para estas ligas e para os campeonatos que organizam e participam. Dos 62 municípios do Amazonas, 54 mantêm ligas ativas, ou seja, organizam campeonatos amadores ${ }^{2}$. Estes campeonatos seguem as regras básicas do futebol internacional, mas têm sua organização, fórmula de disputa e regulamento livres, como comenta José Roberto Moreira da Rocha, secretário do Tribunal de Justiça Desportiva do Amazonas.

\begin{abstract}
A Federação Amazonense de Futebol, por meio de seu presidente, Seu Dissica [Valério] Tomaz, tem algumas coisas fundamentais. Por exemplo, interferir na gerência destas ligas: ele não interfere, ele apoia as coisas que as ligas querem fazer. Ele dá o suporte para que as ligas façam isso, mas não para interferir no gerenciamento de campeonatos, porque cada cidade destas tem uma característica: os campeonatos são diferentes, têm regulamentos próprios, são premiações próprias. Então, ele não interfere nestas ligas. Esta comunicação entre Federação e liga é de apoio. [...]. A Federação só apoia as atividades das ligas. Ela não tem esta gerência de dizer "faça assim". E a outra característica é que a Federação Amazonense de Futebol é muito ligada às ligas, dá muito apoio às ligas. Todas as horas que os presidentes de ligas necessitam de uma informação, a Federação está sempre pronta para ajudar, exatamente por uma coisa interessante: a eleição da Federação Amazonense de Futebol é feita através das ligas, porque no estatuto da Federação não tem uma forma de votar em que o voto do profissional tenha valor por cinco votos e as ligas, cada uma delas votam. Então são 62 , se 49 que estão ativas conosco votarem, então elegem o presidente. Muitas vezes alguns candidatos se aventuram pelas margens dos rios em busca destes votos, para que possam ser eleitos presidente da Federação, mas como o apoio do Presidente Dissica é muito grande a respeito das ligas - ele tem uma maneira muito democrática de fazer. Quando vai fazer um campeonato como a Copa dos Rios, ele reúne os presidentes das ligas e diz assim: “como é que vocês querem?". (Informação verbal) $)^{3}$.
\end{abstract}

discurso de José Roberto Moreira da Rocha, no que se refere à

Federação Amazonense de Futebol - FAF. Ligas. (http://www.faf-am.com.br/liga1.html). Acesso em 01/04/2015.

Rocha, José Roberto Moreira da. Entrevista ao autor. Manaus, 23 set. 2008. Informação verbal.

R. Ra'e Ga - Curitiba, v. 35, p.288 - 313 , Dez/2015 
relação que a FAF mantém com as ligas, é ambíguo. O enunciador fala do lugar de membro da FAF, mas seu discurso expressa tanto as coerções da formação discursiva quanto opiniões próprias. Isto pode ser observado quando fala da política institucional em relação às ligas, bem como da importância dada à centralidade subterrânea entre elas e a FAF. Ao mesmo tempo em que procura legitimar o trabalho da FAF em relação às ligas, alegando apoio e gerenciamento democrático por parte do presidente Dissica Valério Tomaz, José Roberto Moreira da Rocha revela interesses políticos por trás do apoio às ligas. Mesmo havendo interesses nos votos das ligas, o fato de que elas têm certa autonomia para gerenciar seus campeonatos, revela uma organização reticular, que se expressa através das territorialidades das ligas. Além disso, a equiparação dos votos das ligas com os clubes profissionais demonstra a força política, bem como simbólica, que o futebol amador possui dentro da FAF e perante as comunidades. José Roberto Moreira da Rocha procura explicar, em partes, a força do futebol amador, utilizando o argumento da fraqueza do profissional, mas, sobretudo, pelo caráter comunitário de diversão que o futebol amador no Amazonas promove.

\footnotetext{
Acontece que o futebol amador é feito na comunidade. As comunidades em si se reúnem e avisa o futebol amador. O futebol profissional é visto com fins lucrativos. Você vê que o amador é feito por pessoas que gostam de futebol. $\mathrm{O}$ outro é feito por profissionais, que querem ganhar dinheiro encima disso. Então, no interior, devido aos parcos recursos que têm por lá, eles têm esta dificuldade de formar futebol profissional, até por não acreditar muito que aquilo ali vai dar futuro pra um rapaz de 18 ou 20 anos. Então, o amador lá, dependendo do município dele, às vezes por uma garrafa de cerveja, uma garrafa de cachaça, um quilo de farinha, ele vai jogar o futebol dele. Ele se diverte com aquilo. (Informação verbal) ${ }^{4}$.
}

Apesar de todas as ligas conservarem esta dimensão comunitária, cada uma delas possui peculiaridades. Uma das mais tradicionais e estruturadas vinculadas à FAF é a Associação Liga Desportiva de Parintins (Alepin). O Campeonato Parintinense de Futebol acontece desde 1948, ano da fundação de alguns dos clubes que participam até hoje da competição ${ }^{5}$, como Amazonas, Nacional, Sul América e Juventude Atlética Católica (JAC) (Figura 1).

Rocha, José Roberto Moreira da. Entrevista ao autor. Manaus, 23 set. 2008. Informação verbal. O Campeonato Parintinense voltou a ser disputado em 2015 depois de um período de interrupção entre 2011 e 2014. 


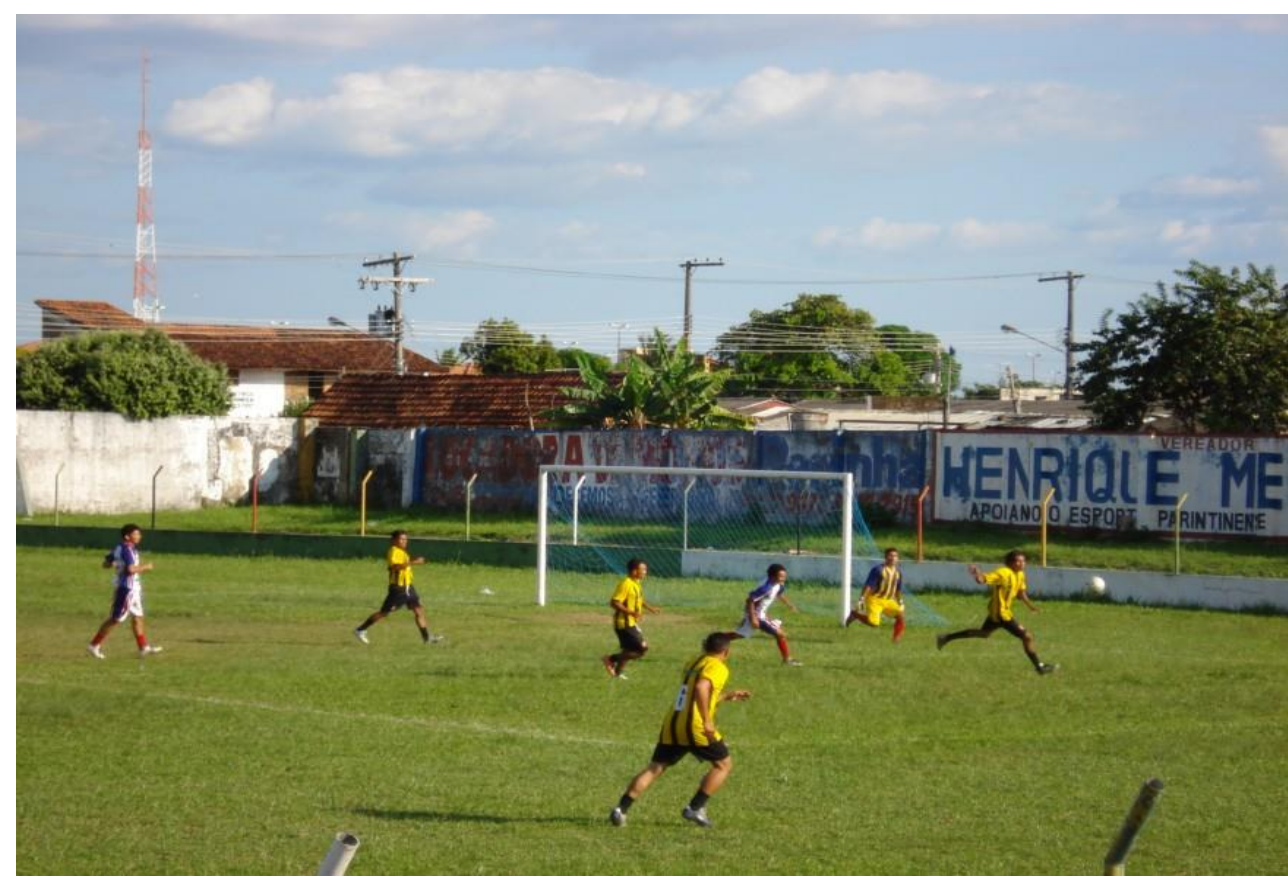

FIGURA 1 - JOGO PELO CAMPEONATO DA ALEPIN 2007

Fonte: $\mathrm{O}$ autor.

Estes passaram a fazer parte da vida cotidiana local, sendo capazes de gerar momentos de presença (LEFEBRE, 2006) e de criar tribos (MAFFESOLI, 2006; 2007) em uma cidade que possui sua socialidade e sua espacialidade pautadas essencialmente no Festival Folclórico de Parintins e na dualidade dos bois-bumbás Caprichoso e Garantido. O futebol, inclusive, participou de forma central na construção da tradição do festival dos bois-bumbás. Os primeiros festivais foram realizados na sede da Juventude Atlética Católica (JAC), passando, posteriormente, para o Estádio Tupy Catanhede. Estádio este que é o principal território futebolístico da cidade, mas que, segundo Elton Ferreira da Silva presidente da Alepin em 2007, precisa de melhoramentos. Ao avaliar seu trabalho em frente à Alepin, Elton Ferreira da Silva deixa transparecer em seu discurso um ethos de abnegação, mas também de dúvida quanto à concretização de seus objetivos.

Nossa experiência ainda está em fase de aprimoramento. Nós estamos trabalhando buscando cada dia, cada ano que passa o melhoramento dos trabalhos que nós realizamos aqui diante destas dez equipes, que exigem de nós o empenho e a eficácia, buscando o melhoramento de todos os aspectos do campeonato. Não só do campeonato, mas também do espaço físico. Nós temos um estádio em precárias condições, mas não por falta de interesse nosso. Nós já fizemos, só na minha gestão, dois anos de trabalho aqui nesta 


\begin{abstract}
liga, vários projetos, enviados até pro governo do estado através da Secretaria de Esportes. Nós temos lá um projeto aprovado e até agora não tivemos nenhuma resposta concreta, sempre nós tivemos muitas promessas dos nossos comandantes maiores: políticos da nossa região que verificam aqui as necessidades que nós temos e infelizmente até agora não pudemos receber nenhuma melhoria convincente. Mas trabalhamos com aquilo que podemos, com a força que nós temos. [...]. Toda dificuldade está inserida em questão financeira. [...]. Vamos suprindo as necessidades; vamos pulando as barreiras; e vamos concretizando nosso trabalho. Não sei até quando... Eu tenho ainda quatro anos pela frente pra desenvolver o meu trabalho. Eu espero que eu consiga concluir este trabalho aqui. A comunidade espera de nós; espera a nossa eficiência, buscar o melhor possível para que a gente conclua e deixe o nosso nome marcado na história do futebol parintinense. (Informação verbal) $)^{6}$.
\end{abstract}

O discurso de Elton Ferreira da Silva se insere na formação discursiva dos dirigentes, retomando um tema recorrente que é o do dinheiro público como panaceia. Mesmo em uma situação diversa da dos dirigentes profissionais, o enunciador demonstra que está à espera do dinheiro do estado para resolver os problemas do estádio e da estrutura da liga. Quanto ao futuro sua postura é ambígua, pois ao mesmo tempo em que pretende deixar seu nome na história do futebol local, o dirigente demonstra um pessimismo ao dizer que não sabe se conseguirá dar continuidade a seu trabalho. Outra contradição no discurso de Elton Ferreira da Silva está ligada ao fato que ora ele pende para um ethos futebolístico pautado no social ora para um calcado na socialidade (MAFFESOLI, 2006, 2007). Seus projetos e seu desejo de marcar seu nome na história contrastam com a abnegação demonstrada quando o dirigente fala dos torneios que a Alepin organiza em paralelo à liga, como o Torneio da Santa e a Taça Bumbá.

A importância das ligas de futebol amador nos municípios do interior do Amazonas pode ser exemplificada por uma das formas dos clubes recrutarem os melhores jogadores para suas equipes. Já que os clubes não podem remunerar os jogadores através de contratos, Ihes são oferecidos empregos em troca dos serviços futebolísticos, forma de articulação da espacialização institucional, articulando clube, empresa e jogador. Renato Barros de Jesus, jogador do Santos de Parintins, explica que esta conversão de capital esportivo em capital econômico não é a realidade de todos os jogadores, sendo que muitos jogam apenas pelo amor, tendo dificuldade de se sustentar.

SILVA, Elton Ferreira da. Entrevista ao autor. Parintins, 27 jun. 2007. Informação verbal. 


\begin{abstract}
Muitas vezes uma pessoa só, um dirigente só dentro do clube, no futebol parintinense, ele mesmo arca com todas as despesas. O jogador não tem salário. Alguns só que pegam um privilégio de um patrocinador bom patrociná-lo, Dando um certo dinheiro por mês. Mas. [*] funciona assim mais ou menos: quando a pessoa vê que a pessoa [jogador] é boa, que ele tem um futebol bom, que ele pode ajudar a equipe, ele vai... Se ele tiver uma empresa em Parintins, um comércio, em geral, ele já coloca uma proposta de emprego para este jogador. E ele começa a jogar no time. Alguns não. Alguns realmente ganham um patrocínio: um salário por mês. E outros não. Outros jogam por amor mesmo. Não têm, no caso, remuneração nenhuma, somente o desejo de jogar e a vontade de jogar bola. [...]. Eu não ganho nada. Às vezes eu até ajudo. Porque eu tenho trabalho. Outros amigos meus que jogam são muito carente mesmo e jogam por gostar. (Informação verbal). . .
\end{abstract}

O discurso de Renato demonstra a dificuldade daqueles que procuram seguir carreira no futebol, uma vez que precisam se bancar em outros empregos. Além disso, fala do lugar de um destes jogadores amadores que sonham em se tornar profissionais e serem reconhecidos. A necessidade do reconhecimento fora do município e, ao menos, em Parintins fica clara quando fala sobre a cobertura que as rádios locais dão ao futebol: "Hoje, a rádio, graças a Deus, dá uma mídia melhor para o futebol. []. Isto é o que às vezes motiva o jogador de querer fazer um pouco mais, de querem ser conhecido. Então, isto acaba levando jogador para dentro de campo" (Informação verbal) $)^{8}$. Isto demonstra o quanto o futebol está inserido na vida cotidiana comunitária parintinense e o hedonismo (MAFFESOLI, 2006, 2007) dos jogadores que jogam por uma perspectiva de carreira, mas também pela vontade de serem reconhecidos em Parintins.

\title{
3.3 Copa dos Rios de Seleções
}

Além das ligas municipais, como é o caso de Parintins, há campeonatos intermunicipais, como a Copa dos Rios de Seleções, que é disputada anualmente, sendo que nos anos ímpares há uma limitação de idade até os 19 anos (completados no ano da competição). A Copa dos Rios de Seleções reúne seleções formadas por jogadores vinculados às ligas municipais, que disputam entre si o título de campeão amazonense de futebol amador. Alicelmo

Jesus, Renato Barros. Entrevista ao autor. Parintins, 26 jun. 2007. Informação verbal. Jesus, Renato Barros. Entrevista ao autor. Parintins, 26 jun. 2007. Informação verbal. 
Santos, presidente da Liga Esportiva de Iranduba, explica a dificuldade de selecionar os jogadores para a Copa dos Rios de Seleções: "A cidade de Iranduba tem dimensões continentais [2.215,033 km²], por isso, foi selecionado com muito carinho os jogadores para compor o elenco" ${ }^{9}$. Com área de 150\% do município de São Paulo, Iranduba não é dos maiores municípios do Amazonas. No entanto, a dificuldade de deslocamento (pequena rede rodoviária e má conservação das estradas) faz com que determinadas áreas dos municípios fiquem praticamente isoladas, se organizando através de comunidades ribeirinhas.

Em 2014, a Copa dos Rios de Seleções contou com a participação de 51 municípios dos 61 possíveis $^{10}$, mesmo número de 2013. No discurso dos dirigentes do futebol profissional amazonense as distâncias entre os municípios ou as dificuldades de acesso à região eram vistas não como um limitador, mas como um impossibilitador do desenvolvimento do futebol profissional (GALLEGO CAMPOS, 2010). Isto pode ser constado também no baixo número de equipes do interior no Campeonato Amazonense de futebol profissional. Os dez clubes da Primeira Divisão do Campeonato Amazonense 2015 são distribuídos em apenas cinco ${ }^{11}$ municípios (PLACAR, 2015). Este fator, somado à maciça participação dos municípios na Copa dos Rios de Seleções faz com que Lázaro D'Angelo Pinheiro, diretor técnico e de eventos da FAF (2007) e Diretor de Futebol do Interior da FAF (2015), considere esta copa como o legítimo campeonato estadual: "Para mim é o verdadeiro campeonato amazonense, temos a participação de mais de $90 \%$ dos municípios com seus atletas do Amazonas, verdeiros filhos da região; onde tem a interação de municípios” (Informação verbal) $)^{12}$. Opinião esta endossada por José Roberto

PORTAL Paulo Repórter. 13 jun. 2013c. Pensando no título, equipe do Iranduba busca novos caminhos na disputa da Copa dos Rios de Seleções. (http://pauloreporter.com.br/pensando-no-tituloequipe-do-iranduba-busca-novos-caminhos-na-disputa-da-copa-dos-rios-de-selecoes/). Acesso em $01 / 04 / 2015$.

10 Manaus não disputa a Copa dos Rios de Seleções, que se restringe aos 61 municípios do interior. Em 2014, havia 56 ligas vinculadas à FAF. 54 delas participaram ou da Copa dos Rios de Seleções de 2013 ou da edição de 2014 (51 seleções em cada).

${ }^{11}$ Manaus (Nacional, Fast Clube, São Raimundo, Rio Negro e Manaus); Manacapuru (Operário e Princesa do Solimões); Iranduba (Iranduba); Itacoatiara (Penarol); e Borba (Nacional Borbense) (PLACAR, 2015).

12 Pinheiro, Lázaro D’ Angelo. Entrevista ao autor. Manaus, 31 mar. 2015. Informação verbal. 
Moreira da Rocha:

\begin{abstract}
O futebol amazonense se restringe à capital. Agora nós temos um time em Itacoatiara e um time em Manacapuru, mas é muito pouco. Hoje nós temos 62 municípios no estado do Amazonas - contando com Manaus - e temos 48, 49 que participam da Copa dos Rios, onde tem que ter ligas [municipais]. O Campeonato Amazonense profissional de futebol não é amazonense, pois só é restrito a Manaus e a um ou dois municípios do interior. Não tem a abrangência do estado todo. A Copa dos Rios abrange todo o estado. Enquanto tem algumas ligas que não participam, $50 \%$ já caracteriza-se 0 estado do Amazonas. Então isto é realmente combínio com que seja o campeonato amazonense. Apesar de algumas dificuldades pelas distâncias. As distâncias complicam muito a realização do futebol profissional nestes municípios. (Informação verbal) $)^{13}$.
\end{abstract}

Os dois enunciadores falam do lugar como funcionários da FAF, que promove tanto o futebol amador quanto o profissional no estado. Mesmo assim, demonstram claramente suas opiniões de que o Campeonato Amazonense de futebol profissional não é capaz de integrar o estado como a Copa dos Rios de Seleções o faz. Isto porque o futebol profissional não tem a capacidade de comportar equipes de tantos municípios, bem como tem dificuldades de penetrar efetivamente na vida cotidiana dos amazonenses e se tornar uma manifestação de pulsão gregária, geradora de momentos de presença e de orgiasmo (LEFEBVRE, 2006; MAFFESOLI, 2006, 2007).

A Copa dos Rios de Seleções é disputada em três fases. A primeira, que em 2014 foi disputada em 14 sedes (grupos de três ou quatro times), é subregional, de acordo com os rios que banham os municípios e a proximidade entre eles. As sete regiões são estabelecidas através dos rios: Alto Solimões, Médio Solimões, Baixo Solimões, Negro, Madeira, Purus e Baixo Amazonas, entre outros. Nas duas primeiras fases as sedes devem arcar com: hospedagem e alimentação das delegações (limite de 25 membros) e dos árbitros visitantes; transporte interno das delegações e da arbitragem do porto/aeroporto até o alojamento e deste até o estádio; pagamento da arbitragem; custos operacionais (FAF, 2014b). A renda com bilheteria e patrocínio fica com as ligas sedes.

Mesmo procurando agrupar as seleções geograficamente, equipes viajam durante dias pelos rios do estado para disputar as partidas. Estas

Rocha, José Roberto Moreira da. Entrevista ao autor. Manaus, 23 set. 2008. Informação verbal.

R. Ra'e Ga - Curitiba, v. 35, p.288 - 313 , Dez/2015 
viagens acabam se constituindo em rompimentos com o cotidiano, pois muitos jogadores precisam pedir licença de seus trabalhos por dias e até semanas devido à duração das viagens. As viagens são consideradas como fator fundamental para a elaboração da tabela da Copa dos Rios de Seleções, conforme explica Lázaro D'Angelo Pinheiro: “Alguns times de municípios são mais próximos com 6 ou 12 horas de viagem, mas outros a equipe passa de 3 , 4 e 5 dias viajando de barco. Por exemplo, a cidade de Eirunepé para se deslocar só vai de avião. Por isso, nós ficamos ligando para verificar a proximidade das cidades para montagem da tabela ${ }^{14}$.

A segunda fase, com os 24 classificados na primeira fase é disputada em municípios do interior. São formados seis grupos de quatro seleções, também considerando a proximidade geográfica dos municípios classificados. Já a última fase reúne as oito melhores seleções das fases anteriores, independentemente da localização geográfica. As oito seleções jogam em sistema de eliminatório de jogo único. Nesta fase, a FAF arca com todas as despesas (das seleções, da arbitragem e dos custos operacionais).

A Final é disputada, em geral, em Manaus. O time vencedor da Copa dos Rios de Seleções ganha um troféu e medalhas douradas, mais $R \$ 5.000^{15}$. Mais do que isto, há um grande valor simbólico em se vencer tal torneio, pois é uma maneira de enaltecer o nome do município, bem como dos campeões se tornarem mais conhecidos e socialmente valorizados na vida cotidiana local. Segundo Lázaro D'Angelo Pinheiro, vencer a Copa dos Rios para as seleções dos municípios "é como ganhar a Copa do Mundo, carro de bombeiros, etc."

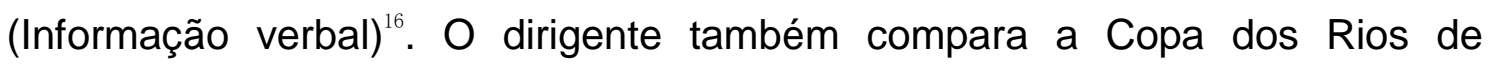
Seleções com a Copa do Brasil, quando afirma que aquela tem "a importância de uma Copa do Brasil para os clubes. Esta é a importância de uma Copa dos Rios para os municípios” (Informação verbal) ${ }^{17}$. É possível observar uma forte

PORTAL Paulo Repórter. 06 jun. 2013a. Diretor de futebol da FAF espera que a Copa dos Rios revele bons jogadores para o AM. (http://pauloreporter.com.br/diretor-de-futebol-da-faf-espera-que-a-copados-rios-revele-bons-jogadores-para-o-am/). Acesso em 01/04/2015.

15 O vice-campeão ganha troféus e medalhas prateadas, mais $R \$ 4.000$; o terceiro recebe troféus e medalhas bronze, além de $\mathrm{R} \$ 3.000$; e o quarto ganha $\mathrm{R} \$ 1.000$ (FAF, 2014b).

Pinheiro, Lázaro D’ Angelo. Entrevista ao autor. Manaus, 31 mar. 2015. Informação verbal.

Pinheiro, Lázaro D’ Angelo. Entrevista ao autor. Manaus, 31 mar. 2015. Informação verbal. 
relação entre a espacialização discursiva e a espacialização institucional no discurso de Lázaro D'Angelo Pinheiro. Ele utiliza referências nacionais (Copa do Brasil) e mundiais (Copa do Mundo). Esta referência corrobora identidades

pós-modernas de caráter glocal, um híbrido entre o localismo (pertencimento a uma comunidade local, a uma tribo) e o globalismo (sentimento de pertença a um grupo maior, a uma massa) (MAFFESOLI, 2006; HAESBAERT, 2008). Já as referências nacionais demonstram o pertencimento do dirigente à $F A F$, que está inserida na CBF, bem como demonstra que, simbolicamente, as competições nacionais não fazem parte da realidade do futebol amazonense, uma vez que as participações dos clubes deste estado são breves e sem grandes perspectivas de obtenção de resultados expressivos.

A Copa dos Rios de Seleções reforça os laços comunitários locais, pois as seleções representam os municípios, tendo estes, na maior parte dos casos, baixa população. Portanto, os jogadores - que precisam comprovar residência no município para participar do campeonato - são conhecidos e possuem um contato direto e cotidiano com a comunidade. Além disto, a Copa dos Rios de Seleções celebra uma complicada integração amazônida, já que as distâncias entre os municípios é muito grande e o futebol profissional não se demonstra capaz de realizar tal conexão. O futebol amador juntamente aos festejos são elementos fundamentais para a construção de uma proxemia amazonense (e amazônida), pois são capazes de aglutinar massas em torno de uma celebração orgiástica (até as festas religiosas apresentam esta dimensão em paralelo) e definir territorialidades culturais (HAESBAERT, 2003, 2008; MAFFESOLI, 2006, 2007; GALLEGO CAMPOS, 2010).

\subsection{Espacialização da Copa dos Rios de Seleções}

A Copa dos Rios de Seleções se organiza a partir da centralidade subterrânea e desta forma se organiza todo o futebol amador do Amazonas (GALLEGO CAMPOS, 2010). A espacialização institucional do futebol amador do Amazonas é fundamentalmente reticular e baseada na potência, convivendo com a política institucional oficial do sistema Fifa-IB/CBF/FAF. A Copa dos Rios de Seleções só é possível devido à organização das comunidades, dos 
municípios e ligas. A FAF organiza e legitima a competição, mas ela não ocorreria sem a existência de ligas municipais que, por sua vez, organizam campeonatos municipais e se mantêm com recursos próprios.

A primeira e a segunda fase da Copa dos Rios de Seleções é bancada pelos municípios que se voluntariam a ser sedes (FAF, 2013b, 2014b). A sede deve disponibilizar alojamento e transporte para as seleções visitantes. Desta

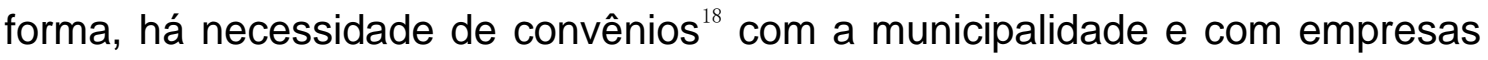
locais, reforçando os laços proxêmicos próprios do futebol amador (MAFFESOLI, 2006, 2007; GALLEGO CAMPOS, 2010). Esta é uma importante expressão da espacialização das práticas do futebol, demonstrando territorialidades calcadas no envolvimento comunitário não apenas no jogar (as seleções são compostas por jogadores do próprio município), mas também na organização da competição e no torcer (poder torcer pelo seu município passa pelo reconhecimento do esforço das outras seleções em disputarem a competição, bem como pelo reconhecimento do município em sediar o torneio).

Além disto, a arbitragem é de responsabilidade das ligas, tendo cada uma que disponibilizar quatro árbitros (um árbitro, dois assistentes e um árbitro reserva). Apesar de ser remunerada, a arbitragem se pauta no ethos amador, pois além das quantias serem baixas ${ }^{19}$, os árbitros também têm que se deslocar de barco durante muitas horas ou dias, acompanhando a delegação de seus municípios.

A FAF tem papel fundamental para dar credibilidade ao campeonato, disputado nos últimos dois anos (2013 e 2014) por 88,5\% dos municípios possíveis (82\% em cada uma das edições) e por $96,5 \%$ dos municípios que têm ligas ativas (Cartograma 1). Rubens de Castro, presidente da Liga Esportiva de Maraã reconhece a importância do trabalho feito pela FAF:

\footnotetext{
Muitos atletas do interior do Amazonas precisam de uma oportunidade, inclusive essa categoria vem dando chance a muitas pessoas. A seleção de Maraã está se preparando bem fisicamente para conseguir bons resultados. $\mathrm{O}$ esporte amazonense tem que ser cada vez mais engrandecido, porque 0
}

O Regulamento da Copa dos Rios de Seleções exige a entrega de documento dos prefeitos dos municípios-sede “comprometendo-se a patrocinar o grupo" (FAF 2014b, p. 3).

19 A liga sede remunera a arbitragem com os seguintes valores: árbitro ( $R \$ 100)$, assistentes $(R \$ 60)$, quarto árbitro ( $R \$ 40)$, coordenador ( $R \$ 120)$ (FAF 2014b). 


\section{LIGAS MUNICIPAIS E COPA DOS RIOS DE SELEÇÕES: INTEGRAÇÃO DO ESPAÇO AMAZONENSE ATRAVÉS DA CENTRALIDADE SUBTERRÂNEA}

nosso futebol está um pouco esquecido, mas com trabalho da FAF e a vinda da Copa do Mundo, creio que o estado dará um passo muito importante para mudar tudo isso ${ }^{20}$.

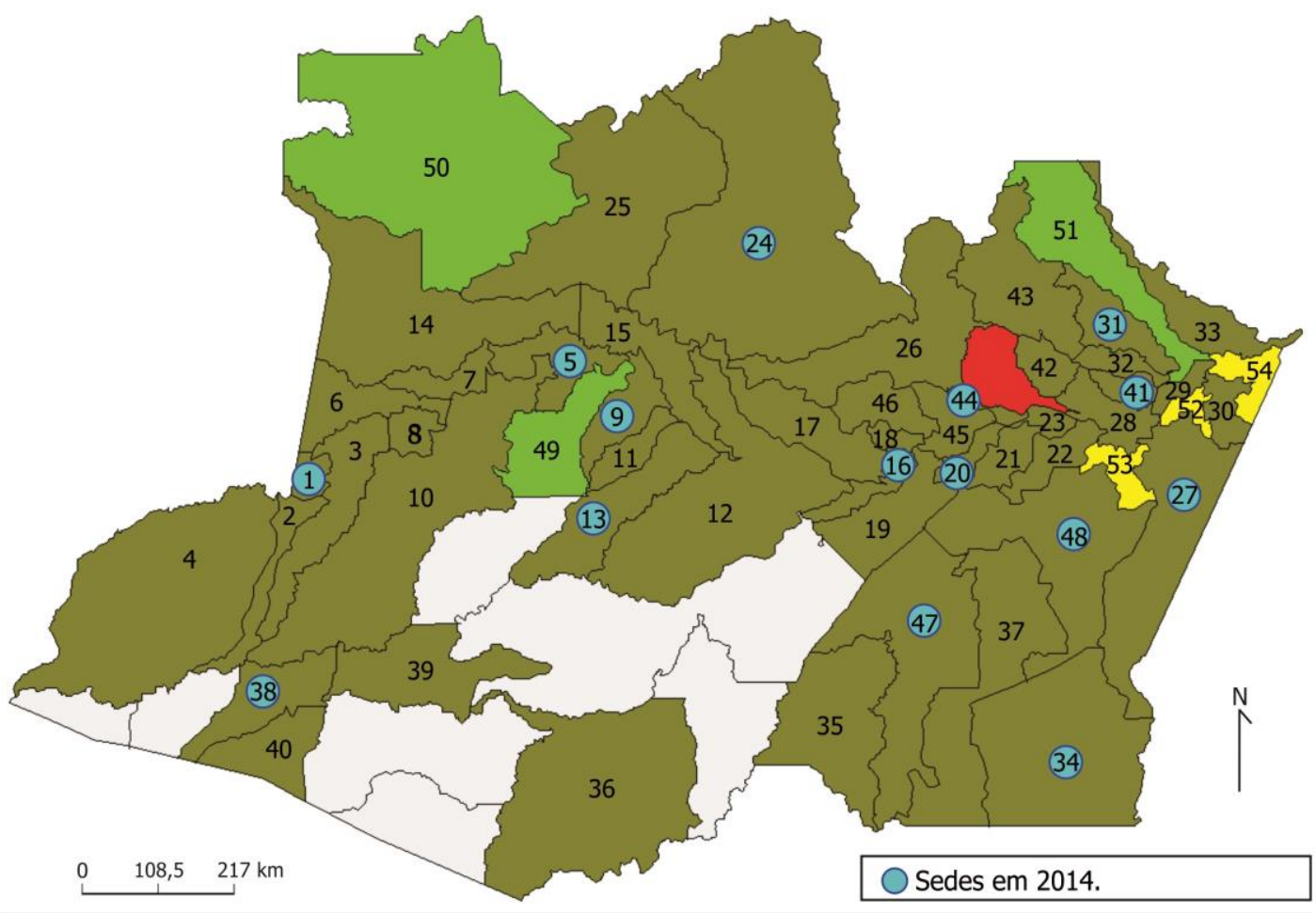

\section{$\square$ Manaus}

Participaram da Copa dos Rios 2013 e 2014

Grupo A1: 1. Tabatinga (sede), 2. Benjamin Constant, 3. São Paulo de Olivença, 4. Atalaia do Norte.

Grupo A2: 5. Fonte Boa (sede), 6. Santo Antônio do Içá, 7. Tonantins, 8. Amaturá.

Grupo A3: 9. Uarini (sede), 10. Jutaí, 11. Alvarães, 12. Coari.

Grupo A4: 13. Tefé (sede), 14. Japurá, 15. Maraã.

Grupo A5: 16. Anori (sede), 17. Codajás, 18. Anamã, 19. Beruri.

Grupo A6: 20. Manaquiri (sede), 21. Careiro Castanho, 22. Autazes, 23. Careiro da Várzea.

Grupo A7: 24. Barcelos (sede), 25. Santa Isabel do Rio Negro, 26. Novo Airão.

Grupo A8: 27. Maués (sede), 28. Itacoatiara, 29. Urucurituba, 30. Barreirinha.

Grupo A9: 31. São Sebastião do Uatamã (sede), 32. Itapiranga, 33. Nhamundá.

Grupo A10: 34. Apuí (sede), 35. Humaitá, 36. Lábrea, 37. Novo Airipuanã.

Grupo A11: 38. Eirunepé (sede), 39. Itamarati, 40. Envira.

Grupo A12: 41. Silves (sede), 42. Rio Preto da Eva, 43. Presidente Fiqueiredo.

Grupo A13: 44. Iranduba (sede), 45. Manacapuru, 46. Caapiranga.

Grupo A14: 47. Manicoré (sede), 48. Borba (sede).

Participaram só da Copa dos Rios 2014 - 49. Juruá (grupo A4), 50. São Gabriel da Cachoeira (grupo A7) 51. Urucará (grupo A9).

Participaram só da Copa dos Rios 2013 - 52. Boa Vista de Ramos, 53. Nova Olinda do Norte, 54. Parintins.

\section{CARTOGRAMA 1 - PARTICIPAÇÃO NAS COPAS DOS RIOS DE SELEÇÕES}

\section{E 2014}

Fonte: O autor, baseado em FAF (2013a, 2014b).

20 Portal Paulo Repórter. 12 jun. 2013b. Dirigente de Maraã diz que Copa dos Rios é a chance de revelar bons jogadores no interior do AM. (http://pauloreporter.com.br/dirigente-de-maraa-diz-quecopa-dos-rios-e-a-chance-de-revelar-bons-jogadores-no-interior-do-am/). Acesso em 01/04/2015. 
A FAF mantém uma diretoria específica para o futebol no interior, reconhecendo a importância do futebol amador no estado, mas também o fato de que o Campeonato Amazonense de futebol profissional é bastante restrito à capital. Simbolicamente, esta concentração é compensada pela disputa da final da Copa dos Rios de Seleções em Manaus, marcando territorialidades do futebol amador do interior em importantes territórios futebolísticos em Manaus (estádios utilizados pelos clubes profissionais). Nas finais, há grande mobilização não apenas das delegações das seleções, mas também de torcedores que se deslocam de seus municípios de origem para prestigiar a seleção que representa sua terra.

A espacialização discursiva da Copa dos Rios de Seleções de integração do Amazonas e de suas comunidades se efetiva na prática de modo a criar estruturações identitárias de pertencimento ao estado, à comunidade local (tribos) e à massa global de praticantes de futebol. Este torneio é um dos poucos eventos que consegue reunir tantos municípios do estado e envolver diferentes atores sociais ${ }^{21}$ (desde os que participam diretamente jogando ou apitando, até os que participam indiretamente, como o comércio, rede hoteleira, restaurantes, patrocinadores, torcedores, etc.).

\section{CONSIDERAÇÕES FINAIS}

Percebe-se uma forte ligação entre o futebol amador e a vida cotidiana dos municípios do Amazonas. Neste sentido, as ligas possuem grande importância, pois organizam as espacializações prática e institucional do futebol. Elas tornam possíveis a realização de campeonatos em municípios em que o futebol profissional é inexistente ou incipiente, bem como a formação de seleções para representar tais municípios na Copa dos Rios de Seleções. Apesar de estarem vinculadas à FAF e, portanto, à organização oficial do futebol pautada na política institucional e em relações calcadas no poder, as ligas só se efetivam através da centralidade subterrânea. Esta organização reticular é que permite que a FAF e, portanto, o sistema Fifa-IB chegue aos

Em 2013, a FAF previa a participação de mais de 1.500 jogadores e 255 membros da comissão técnica (PORTAL, 2015a). 
municípios do interior do Amazonas.

A Copa dos Rios de Seleções também se baseia na centralidade subterrânea e na potência, pois somente ocorre devido ao comprometimento das ligas locais, do poder público dos municípios (sedes e participantes) e da comunidade em geral (empresários, rede hoteleira, restaurantes, etc.). O status de verdadeiro campeonato amazonense, atribuído dentro da própria FAF, que organiza o Campeonato Amazonense (profissional), demonstra a penetração deste torneio na vida cotidiana das comunidades do interior do Amazonas e a efetividade da integração de um estado, que possui dificuldade neste aspecto devido à sua dimensão e à precária rede de transportes.

Compreender a complexidade das ligas e da Copa dos Rios de seleções não ajuda apenas a avançar no estudo do futebol amador, mas também no entendimento de aspectos culturais, sociais, econômicos e esportivos do estado do Amazonas. Se esta forma de organização é peculiar ao Amazonas, outros estados, municípios e regiões da Amazônia encontram diferentes maneiras de promover sua integração através do futebol amador e estas merecem uma maior preocupação da academia, uma vez que isto ajudará a melhor apreender a realidade socioespacial destes. 


\section{REFERÊNCIAS}

ALABARCES, P. Veinte años de ciencias sociales y deportes, diez años después. Revista da ALESDE. Curitiba, v. 1, n. 1: 11-22, 2011.

ALMEIDA, M. B. O esporte como matriz da sociabilidade espontânea: um olhar pelo referencial habermasiano. Revista da ALESDE. Curitiba, v. 1, n. 1: 100110, 2011.

DAMATTA, R. Em torno da dialética entre igualdade e hierarquia: notas sobre as imagens e representações dos Jogos Olímpicos e do futebol no Brasil. Antropolítica. Rio de Janeiro, v. 1, n. 14: 17-39, 2003.

DAMO, A. S. Dom, amor e dinheiro no futebol de espetáculo. Revista Brasileira de Ciências Sociais. São Paulo, v. 23: 139-150, 2008.

. Paixão partilhada e participativa: o caso do futebol. História Questões e Debates. Curitiba, v. 57: 45-72, 2012.

Senso de jogo. Esporte e Sociedade. Rio de Janeiro, v. 1, n. 1: 1-36, 2005.

FOUCAULT, M. A ordem do discurso: aula inaugural no Collège de France em 2 de dezembro de 1970. São Paulo: Loyola, 2007.

2006.

O nascimento da clínica. Rio de Janeiro: Forense Universitária,

FRANCO JÚNIOR, H. Brasil, país do futebol?. Revista USP. São Paulo, v. 99: 45-56, 2013.

GALLEGO CAMPOS, F. R. Futebol e festejos no espaço de representação do futebol amador amazonense. Geotextos. Salvador, v. 6: 141-159, 2010.

- Geografia e Futebol? Espaço de representação do futebol e rede sócio-espacial do futebol. Terr@ Plural. Ponta Grossa, v. 2: 249-265, 2008.

O espaço de representação do futebol: uma apreensão do futebol como elemento sociocultural e espacial. Ra e Ga. Curitiba, v. 11: 35-49, 2006.

HAESBAERT, R. Da Desterritorialização à Multiterritorialidade. Boletim Gaúcho de Geografia. Porto Alegre, v. 29, n.1: 11-24, 2003.

. Território e Multiterritorialidade: um debate. GEOgraphia. Rio de Janeiro, v. 17: 19-45, 2008.

LEFEBVRE, H. La presencia y la ausencia: contribución a la teoría de las representaciones. México: FCE, 2006. 
MAFFESOLI, M. O tempo das tribos: o declínio do individualismo nas sociedades de massa. Rio de Janeiro: Forense Universitária, 2006.

Tribalismo pós-moderno: da identidade às identificações. Ciências

Sociais Unisinos. São Leopoldo, v. 43, n. 1: 97-102, 2007.

MAINGUENEAU, D. Novas tendências em análise do discurso. Campinas: Pontes, 1997.

MASCARENHAS, G. Football, globalisation and local identity in Brazil. Esporte e Sociedade. Rio de Janeiro, v. 3: 1-14, 1999.

. Um jogo decisivo, mas que não termina: a disputa pelo sentido da cidade nos estádios de futebol. Cidades. Presidente Prudente, v. 10, n. 17: 142-170, 2013.

MOSCOVICI, S. Representações sociais: investigações em psicologia social. Petrópolis: Vozes, 2003.

ORLANDI, E. L. P. Claude Lévi-Strauss, Michel Pêcheux e o estruturalismo. ComCiência. Campinas, v. 108, 2009.

1998.

O próprio da análise do discurso. Escritos. Campinas, v. 3: 17-22,

PÊCHEUX, M. Semântica e discurso: uma crítica à afirmação do óbvio. Campinas: Unicamp, 2014.

SHIELDS, R. Lefebvre, love and struggle: spatial dialectics. London: Routledge, 1999.

TOLEDO, L. H. Brazilian soccer: symbolic dimensions of its practice. Soccer \& Society. Londres, v. 15: 1-17, 2013.

. Futebol e teoria social: aspectos da produção acadêmica brasileira (1982-2002). Revista Brasileira de Informação Bibliográfica em Ciências Sociais. São Paulo, v. 52: 133-165, 2001.

FONTES PRIMÁRIAS

JESUS, Renato Barros. Entrevista ao autor. Parintins, 26 jun. 2007. Informação verbal.

PINHEIRO, Lázaro D’ Angelo. Entrevista ao autor. Manaus, 23 set. 2008. Informação verbal. 
LIGAS MUNICIPAIS E COPA DOS RIOS DE SELEÇÕES: INTEGRAÇÃO DO ESPAÇO AMAZONENSE ATRAVÉS DA CENTRALIDADE SUBTERRÂNEA

. Entrevista ao autor. Manaus, 31 mar. 2015. Informação verbal.

ROCHA, José Roberto Moreira da. Entrevista ao autor. Manaus, 23 set. 2008. Informação verbal.

SILVA, Elton Ferreira da. Entrevista ao autor. Parintins, 26 jun. 2007. Informação verbal.

\section{FONTES DOCUMENTAIS}

FEDERAÇÃO Amazonense de Futebol - FAF. Ligas. Disponível em: $<$ http://www.faf-am.com.br/liga1.html . Acesso em 01/04/2015.

. Nota Oficial No. 014/13. DTE/FAF. Manaus, 25 abr. 2013a.

Nota Oficial No. 014/14. DTE/FAF. Manaus, 05 jun. 2014a.

XXI Copa dos Rios de Seleções de 2013 - 19 anos: Regulamento. Manaus, 2013b.

2014b.

XXII Copa dos Rios de Seleções - 2014: Regulamento. Manaus,

GLOBOESPORTE. 09 out. 2012. A pesquisa da vez: Manaus-AM. Disponível em: $\quad<$ http://globoesporte.globo.com/platb/teoria-dos-jogos/2012/10/09/apesquisa-da-vez-manausam-exclusivo/>. Acesso em 01/04/2015.

INSTITUTO de Pesquisas do Norte - IPEN. 2012. Times de futebol com maiores torcidas em Manaus. 2012. Disponível em $<$ http://www.ipenmanaus.com/artigos/preferencia futebol.pdf $>$. Acesso em 01/04/2015.

PLACAR. Guia Estaduais 2015. Abril, São Paulo. 2015.

PORTAL Paulo Repórter. 06 jun. 2013a. Diretor de futebol da FAF espera que a Copa dos Rios revele bons jogadores para o AM. Disponível em: $<$ http://pauloreporter.com.br/diretor-de-futebol-da-faf-espera-que-a-copa-dosrios-revele-bons-jogadores-para-o-am/>. Acesso em 01/04/2015.

. 12 jun. 2013b. Dirigente de Maraã diz que Copa dos Rios é a chance de revelar bons jogadores no interior do AM. Disponível em: $<$ http://pauloreporter.com.br/dirigente-de-maraa-diz-que-copa-dos-rios-e-achance-de-revelar-bons-jogadores-no-interior-do-am/z. Acesso em 01/04/2015. 
LIGAS MUNICIPAIS E COPA DOS RIOS DE SELEÇÕES: INTEGRAÇÃO DO ESPAÇO AMAZONENSE ATRAVÉS DA CENTRALIDADE SUBTERRÂNEA

. 13 jun. 2013c. Pensando no título, equipe do Iranduba busca novos caminhos na disputa da Copa dos Rios de Seleções. Disponível em: $<$ http://pauloreporter.com.br/pensando-no-titulo-equipe-do-iranduba-buscanovos-caminhos-na-disputa-da-copa-dos-rios-de-selecoes/>. Acesso em 01/04/2015. 